Journal of Social Sciences 7 (2): 152-157, 2011

ISSN 1549-3652

(C) 2010 Science Publications

\title{
A Study of Public Health Awareness among the Elderly in an Industrially Developing Country
}

\author{
${ }^{1}$ Ruhana Zainuddin, ${ }^{1}$ Norshaieda Abdullah, ${ }^{2}$ Syaidatul Zarina Mat Din, \\ ${ }^{3}$ Paul H.P. Yeow and ${ }^{4}$ H.S. Loo \\ ${ }^{1}$ Faculty of Computer and Mathematical Sciences, Universiti Teknologi MARA, KM 12 Jalan Muar, \\ 85009 Segamat, Johor, Malaysia \\ ${ }^{2}$ Faculty of Business Management, Universiti Teknologi MARA, KM 12 Jalan Muar, \\ 85009 Segamat, Johor, Malaysia \\ ${ }^{3}$ Monash University, Jalan Lagoon Selatan, 46150 Bandar Sunway, Selangor, Malaysia \\ ${ }^{4}$ Faculty of Mechanical Engineering, Universiti Teknologi MARA \\ 40450 Shah Alam, Selangor Malaysia
}

\begin{abstract}
Problem statement: The elderly in Industrially Developing Countries (IDC) may encounter problems regarding health. This research is to determine the common diseases or ailments experienced by adults over the age of 40. Approach: A sample of 150 respondents was taken from three states in Malaysia, an IDC. Demographic profiles such as age, gender and race were obtained and questions regarding attentiveness and awareness of health were asked. Four hypotheses were tested. Multiple regression analysis was employed to analyze the data. Results: The result showed $85.8 \%$ of respondents had one or more diseases. Among them, men and women had different diseases and different race had different disease. In addition, healthy lifestyle, good diet and weight management were determinants of health awareness. Conclusion: The results are very useful for health administrators to plan strategies to improve public health in Malaysia. The study can be replicated in other countries using the same method to derive similar benefits.
\end{abstract}

Key words: Health awareness, Industrially Developing Countries (IDC), public health policy

\section{INTRODUCTION}

Health is a very important topic to be discussed. A healthy body brings happiness to life and the family. A study done by Issa et al. (2009) in developing country showed that there is a great deal of failure in terms of qualified personnel, lack of planning and proper justification. Malaysia as a developing country also struggling with same problem especially in health issues. Infectious diseases are mostly under control and non-communicable diseases such as diabetes, Coronary Heart Disease (CHD) and hypertension have become the leading causes of mortality and morbidity. This disease pattern is expected to magnify and increase with the current demographic trends of aging and urbanization.

A study by the Health Ministry from 1990-2005 revealed a $135 \%$ increase in CHD among women, as found that $46 \%$ of women around the age of 50 suffered from CHD compared with 10\% from breast cancer. Besides, $31 \%$ of women around that age had died of
CHD while only $3 \%$ died from breast cancer. Among the women who had a higher risk of getting CHD, many were obese, diabetics and smokers, most of whom had reached menopause, leading a sedentary lifestyle. This study and several other studies indicated that prevalence of diseases among adults 40 years old and above in Malaysia. The present study investigated the types of common diseases such as CHD, kidney problems, high blood pressure, diabetes and cancer according to gender, race and age and smoking habits in this age group. It is intended to identify the possible relationship between these diseases and moderating variables such as gender, race and smoking habit. In addition, it can be useful to identify the determinants of health awareness among the adults in this age group. These findings could be useful for the country's health administrators in developing programmers to improve public health. They are also useful to other researchers as the present research could help to identify serious health trends which could be a high impact research area.

Corresponding Author: Ruhana Zainuddin, Faculty of Information Technology and Quantitative Science, Universiti Teknologi MARA, 40450 Shah Alam, Selangor Malaysia 


\section{J. Social Sci., 7 (2): 152-157, 2011}

Hypothesis: As this is the first study, there are only a few (four) hypotheses to be tested as below:

$\mathrm{H}_{1}$ : There is no relationship between types of disease and gender

$\mathrm{HO}_{2}$ : There is no relationship between types of disease and race

$\mathrm{HO}_{3}$ : There is no relationship between types of disease and smoking habit

$\mathrm{H}_{4}$ : None of the variables make a significant contribution to the awareness about health of the respondents

Review of literature: Hayes et al. (2006), stated that more than one third (36.5\%) of all women had multiple risk factors (i.e., $\geq 2$ from diabetes, smoking habits, high blood pressure, high cholesterol, obesity, or physical inactivity). The age-standardized prevalence of multiple risk factors was the lowest in the whites and Asians. After adjustment for age, income, education and health coverage, the odds for multiple risk factors was greater in black $(\mathrm{OR}=1.53,95 \% \mathrm{CI}=1.42-1.64)$ and Native American women $(\mathrm{OR}=1.36,95 \% \mathrm{CI}=1.11-1.67)$ and lower for Hispanic women $(\mathrm{OR}=0.83,95 \% \mathrm{CI}=0.76$ $0.91)$ compared to white women.

Prevalence estimates and odds of multiple risk factors increased with age; decreased with education, income and employment; lower in those with no health coverage. Smoking was more common in younger women and older women were more likely to have medical conditions (high blood pressure, high cholesterol, or diabetes) and they were physically inactive. Over one third of US women have two or more risk factors for CHD and stroke.

According to Health Ministry's statistics, about 46 per cent of Malaysian women are suffering from CHD and those who are menopausal or have their ovaries removed are in high risk of getting it. Datin Seri Rosmah Mansor (who quoted the Health Ministry's statistics) said women above 55 and with family history of having the disease is also among the high-risk group.

A research by Awomeso et al. (2010) suggested that to achieve healthy environment need to use proper disposal technique water supply contaminated. In developing country filthy habit showed low level of health awareness. Because of this habit, various sources of water supply are similarly contaminated and this may pass on a serious infection.

Sumalatha and Ramakrishnaiah (2004) found that there was a gender bias in U.S history where women were ignored and when they were mentioned, they were treated perfunctionally. Women were not acknowledge in any leading roles and they were treated as beng supplementary to American history. Women were frequently portrayed in stereotypical ways and their socio-economic experiences are treated as anomalous or deviant.

Chee et al. (2004) examined the factors related to overweight in a cross-sectional survey that included 1612 female workers from 10 large electronics assembly factories in Peninsular Malaysia. Respondents were Malaysian citizens, direct production workers below the supervisory level and had worked at least for a year in the factory where they were employed. Prevalence of overweight and mean Body Mass Index (BMI) for younger age groups were similar to the Malay women in the nationwide National Health and Morbidity Survey II, but the older age groups in this study had higher overweight prevalence and mean BMI than the national sample. Electronics women workers faced a higher risk of overweight and were an important group for nutrition intervention.

According to Calle et al. (2003), approximately 900,000 individuals suggested that obesity might account for $14 \%$ of cancers in men and $20 \%$ of cancers in women and in this cohort, the heaviest men and women were $52 \%$ and $62 \%$, respectively, more likely to die of cancer.

Datuk Seri Dr Chua Soi Lek, the former Health Minister of Malaysia stressed on "eat more fruits and vegetables, cut out the fatty stuff" during his nationwide campaign. He said that the latest survey in 2002/03 indicated that the number of overweight adults has doubled to 4.2 million Malaysians and 1.9 million people are now obese. Obesity is now a major concern and must be countered immediately.

An article from Yayasan Jantung Malaysia (the heart foundation of Malaysia) said that around $60 \%$ of all men and about $45 \%$ of all women are overweight or obese. According to the Heart Foundation, 1/3-1/2 of Australians between 20 and 69 years had higher than recommended blood cholesterol levels. This was shown in the number of early deaths. In 1996, over 10,000 people under the age of 70 died of heart and blood vessel diseases.

Kirkland et al. (1999) revealed that smoking and stress were the major causes of CHD (41 and 44\%, respectively); hypertension was only $16 \%$. Men and women did not differ in their awareness of high blood cholesterol (cited by $23 \%$ of participants), smoking (41\%), excess weight $(30 \%)$ or lack of exercise $(28 \%)$ as causes of CHD. A greater proportion of women than men were aware of hypertension (19 v. 12\%) and heredity (31 v. 17\%) as major causes of CHD. Awareness of risk factors was consistently lower in the 
older age group (65-74 v. 55-64 years). Among women, there was greater awareness of the respective risk factors as causes of CHD among those who were smokers (60 v. $35 \%$ of nonsmokers), those who had a Body Mass Index (BMI) of 25 or greater (38 v. $24 \%$ of those with a BMI less than 25) and those who were hypertensive $(22$ v. $17 \%$ of those without hypertension). Those who had experienced a heart attack had greater awareness of the major causes of CHD than those who had not. This pattern was stronger among women than among men. Of those in whom elevated cholesterol level was identified during the course of the study, $62 \%$ of men and $67 \%$ of women were unaware of their cholesterol status. Of those in whom high blood pressure was diagnosed, $43 \%$ of men and $33 \%$ of women were unaware of their hypertensive status. Awareness of the major causes of cardiovascular disease is low among older Canadians, especially among men and in those 65-74 years of age.

According to Geok (1994) the types and prevalence of CHD risk factors vary somewhat among the three main ethnic groups in peninsular Malaysia. Indians consistently showed the highest prevalence for hypercholesterolemia and diabetes mellitus. Among the Malays, a relatively high prevalence of hypertension and hypertriglyceridemia had been reported. Overweight was also a risk factor among the Indians and Malays. In general, Chinese tended to have a lower prevalence for these CHD risk factors than the Indians and Malays. Parallel to the rapid socio-economic development and urbanization in recent decades was a rise in the percentage of deaths due to cardiovascular disease in peninsular Malaysia, that is, from $1.8 \%$ of total deaths from all causes in 1950 to about $30 \%$ in 1991. CHD accounted for $40 \%$ of all cardiovascular diseases. The mortality rate for CHD was more than doubled between 1965 and 1991, from 24.6 per 100 000-57.2. Naidu et al. (2003) in their research found that Malaysian Indians were more commonly afflicted with CHD. While Indians had been showing the highest CHD mortality rate so far, the rate among the Malays had been increasing most rapidly since 1970, concomitant with the latter's increase in their proportion of the urban population in peninsular Malaysia.

A study on a sample of 573 subjects from a Bahraini population showed that the proportion of diabetics with positive family history of diabetes was high $(41.7 \%)$. The high frequency of positive family history in previously known diabetes subjects $(47.7 \%)$ compared to $29.3 \%$ in newly diagnosed diabetics may be attributed to awareness of the problem among those with positive history of diabetes and to the higher percentage of intermarriage in Bahrain. The nondiabetic subjects had a lower frequency of positive family history (only $23.3 \%$ ). The prevalence of diabetes rose with age. It was observed that the prevalence rate of diabetes among men and women was almost equal in the survey.

A survey by Geiss et al. (2002) found that, in the 1988-1994 period, $71 \%$ (95\% confidence interval $(\mathrm{CI}=$ $\pm 4.4 \%$ ) of all US adults with diabetes had elevated blood pressure. The prevalence of elevated blood pressure increased with age and was high among both men and women and among Mexican Americans, nonHispanic blacks and non-Hispanic whites. Among those with elevated blood pressure, $71 \%(95 \% \mathrm{CI}= \pm 4.1 \%)$ were aware and $57 \%(95 \% \mathrm{CI}= \pm 4.2 \%)$ were treated, but only $12 \%(95 \% \mathrm{CI}= \pm 3.2 \%)$ had mean blood pressure $<130 / 85$ and $45 \%(95 \% \mathrm{CI}= \pm 4.9 \%)$ had mean blood pressure $<140 / 90$. Control of blood pressure was least common among older people.

Lip et al. (1996) in their study reported that there was a significantly lower proportion of reported regular exercise activity amongst the Asian (defined as people of south Asian or Indian subcontinent descent) women and their husbands or partners. This study demonstrated that Asian families were the least likely to take regular exercise and had a lower awareness of cholesterol or dietary content (Fiber, sugar, salt) despite public health campaigns and publicity. They were however the least likely to smoke cigarettes. These ethnic differences may in part explain the higher prevalence of CHD amongst the Asian population in the United Kingdom.

\section{MATERIALS AND METHODS}

Instrument and data analysis: A set of questionnaires was distributed to people in three states in Malaysia. Responses to the questionnaire were anonymous and the subjects were assured about the strict confidential treatment of their responses. The response rate was $100 \%$.

Analysis was done by using SPSS 12.0 program. Descriptive statistics such as frequencies and percentages were used to describe the data regarding respondent demographic profile. Four hypotheses were stated and tested using the Chi-square analysis. Chisquare test was chosen because the two tested variables are nominal or categorical variables.

\section{RESULTS}

Demography: Table 1 shows the demographic characteristics of the subjects by gender. A total of 150 subjects from the three states in Malaysia consist of male $(60 \%)$ and female (40\%). 
J. Social Sci., 7 (2): 152-157, 2011

Table 1: Socio-demographic characteristics of respondents

\begin{tabular}{|c|c|}
\hline Items & Percentage \\
\hline \multicolumn{2}{|l|}{ Gender } \\
\hline Male & 60.0 \\
\hline Female & 40.0 \\
\hline \multicolumn{2}{|l|}{ Age } \\
\hline $40-45$ & 53.0 \\
\hline $46-50$ & 30.0 \\
\hline $51-55$ & 11.3 \\
\hline $56-60$ & 2.0 \\
\hline Above 61 & 3.0 \\
\hline \multicolumn{2}{|l|}{ Race } \\
\hline Malay & 89.0 \\
\hline Chinese & 7.0 \\
\hline Indian & 4.0 \\
\hline \multicolumn{2}{|l|}{ Religion } \\
\hline Islam & 87.3 \\
\hline Buddhist & 8.0 \\
\hline Hindu & 2.0 \\
\hline Christian & 2.7 \\
\hline \multicolumn{2}{|l|}{ Family income in a month } \\
\hline Less than RM1,000 & 22.0 \\
\hline $\mathrm{RM} 1,000$ to $<\mathrm{RM} 2,000$ & 30.7 \\
\hline $\mathrm{RM} 2,000$ to $<\mathrm{RM} 3,000$ & 25.3 \\
\hline $\mathrm{RM} 3,000$ to $<\mathrm{RM} 4,000$ & 6.7 \\
\hline Above RM4, 000 & 15.3 \\
\hline \multicolumn{2}{|l|}{ Job } \\
\hline Government & 33.3 \\
\hline Non-Government & 34.0 \\
\hline Labor & 2.0 \\
\hline Own business & 14.7 \\
\hline Other & 16.0 \\
\hline \multicolumn{2}{|l|}{ Status } \\
\hline Married & 83.0 \\
\hline Widow & 6.0 \\
\hline Widower & 3.0 \\
\hline Polygamy & 3.0 \\
\hline Unmarried & 5.0 \\
\hline \multicolumn{2}{|l|}{ No. of children } \\
\hline None & 6.7 \\
\hline 2-Jan & 23.4 \\
\hline 4-Mar & 42.7 \\
\hline 7-May & 18.7 \\
\hline 9-Aug & 4.7 \\
\hline Above 10 & 2.8 \\
\hline
\end{tabular}

The majority of the subjects (89\%) were Malays. Most of them (30.7\%) earned between RM1, 000-RM1, 999 per month followed by RM2,000-RM2,999 (25.3\%), less than RM1,000 (22\%) and above RM4,000 (15.3\%). Most of the respondents were non-government (34\%) workers, followed by government (33.3\%), own business (14.7\%) and $2 \%$ were labors.

Types of diseases: Overall, prevalence of poor health, heart disease, kidney, high blood pressure, diabetes and cancer came from those who were in 40-45 age groups. Some of the most striking variations in prevalence of these health conditions by age and socio-demographic characteristics are highlighted below.
Table 2: Type of disease and gender

\begin{tabular}{llll}
\hline & Value & DF & Sig. \\
\hline Pearson chi-square & $13.847(\mathrm{a})$ & 6 & 0.031 \\
\hline & & & \\
Table 3: Types of disease and race & DF & Sig. \\
\hline \multicolumn{2}{l}{ Value } & & \\
\hline Pearson chi-square & $35.281(\mathrm{a})$ & 12 & 0.000 \\
\hline
\end{tabular}

This study shows that $85.8 \%$ (very high percentage) of respondents over 40 years of age have one or more diseases. Overall, the occurrence of chronic diseases (heart attack, kidney failure, high blood pressure and diabetes) among men was higher (more than 50\%) except for cancer (20\%). Women had more cancer $(80 \%)$, followed by high blood pressure (48.5\%). This is supported by Chi-square test results which is significant (Table 2). Therefore, the first null hypothesis $\left(\mathrm{HO}_{1}\right)$ was rejected $(\mathrm{Chi}$ square $=13.847$, $\mathrm{p}=<0.05$ ). This means there is a relationship between types of disease and gender.

CHD: Adults aged 40-45 years had more heart disease and prevalence of this disease among men was very high $(90.9 \%)$. It showed that Malays had more heart disease $(45.5 \%)$ while Chinese and Indian were equal $(27.3 \%)$. Most of them were ranged in a middle income group (73.7\%). This is supported by results in Table 3 which shows Chi square test of types of disease by race whereby the second null hypothesis $\left(\mathrm{HO}_{2}\right)$ is rejected, thus there is a relationship between types of disease and race of the respondent.

Kidney: Prevalence of kidney problems among male was higher $(87.5 \%)$ compared to female $(12.5 \%)$. Most of them were Malays (75\%) aged $40-45$ years old. It was also found that those who were married are more likely than unmarried (12.5\%) to have kidney disease. This disease was dominant among medium income group (75\%).

The majority of the respondents who already contracted CHD, high blood pressure and diabetes did not smoke. $75 \%$ of those who smoked had kidney problems. Table 4 shows the chi-square test of types of disease and smoking habit. The third null hypothesis $\left(\mathrm{HO}_{3}\right)$ is rejected (Chi square $\left.=0.023, \mathrm{p}<0.05\right)$. This means there is a relationship between types of disease (CHD, kidney, high blood pressure, diabetes and cancer) and smoking habit.

High blood pressure: It was found that males had more high blood pressure (51.5\%) than females. 
Table 4: Types of disease (CHD, kidney, high blood pressure, diabetes and cancer) and smoking habit

\begin{tabular}{lllr}
\hline & Value & df & Sig. \\
\hline Pearson chi-square & 23.547 & 12 & 0.023 \\
\hline
\end{tabular}

Table 5: Multiple regression analysis

\begin{tabular}{llll}
\hline Variable & Beta & $\mathrm{t}$ & $\mathrm{p}$ \\
\hline Frequency of attack & -0.204 & -2.074 & 0.040 \\
Family disease history & -0.173 & -2.072 & 0.040 \\
Obesity (weight control) & 0.213 & 2.741 & 0.007 \\
Illness reduction attempts & 0.090 & 2.741 & 0.007 \\
Good diet (diet control) & 0.214 & 6.792 & 0.000 \\
Healthy lifestyle practice & 0.332 & 11.058 & 0.000 \\
\hline
\end{tabular}

Comparing between ages it was found that those who were from $40-45$ years old (42.4\%) had more high blood pressure followed by age ranged 46-50 years old $(33.3 \%)$. Most of them were Malays $(90.9 \%)$ from medium income group $(51.5 \%)$. Prevalence of high blood pressure was higher among married people $(93.9 \%)$.

Diabetes: $76.5 \%$ male had diabetes. Prevalence of diabetes was the highest among adults aged $40-45$ years $(47 \%)$ and lowest among those 56 years and over $(5.9 \%)$. It was also the highest among Malay adults (94\%). Medium income group (58.8\%) was more likely than high income group $(35.3 \%)$ to have diabetes. The study showed that most of those who contracted this disease were married (94.1\%).

Cancer: Females aged $46-50$ years $(60 \%)$ were more likely to have cancer than males. Most of them were Malays. Prevalence of cancer was high among medium income group $(80 \%)$. Most of them were married $(60 \%)$.

Determinants of health awareness: For regression model, a stepwise multiple regression analysis was performed with the awareness about health as the dependent variable. Table 5 shows the results of the multiple regression analysis. Test of overall significance was done and it was found that the full model was significant $(\mathrm{F}=11.595, \mathrm{p}<0.05)$. Therefore, the null hypothesis $\left(\mathrm{HO}_{4}\right)$ was rejected.

The result shows that six variables are determinants of health awareness, i.e., (1) Frequency of Attack, (2) Family Disease History, (3) Obesity (Weight Control), (4) Illness Reduction Attempts, (5) Diet Control and (6) Healthy Lifestyle Practice. The total explained variance (model $\mathrm{R}^{2}$ ) was $44.5 \%$. It therefore means that, these six factors affect the health awareness by $44.5 \%$. This shows that people who are concerned about their health will take suitable and good food, try to cure the disease, have frequent attacks or illness. They are obese, inherit disease from family and practice healthy lifestyle.

\section{DISCUSSION}

In an effort to realize the mission of the country to be a developed nation, various steps need to be taken to ensure the society's well being not only from economical or political perspectives, but also that of social and health. To achieve the above objectives, a high level of living and health awareness must be created among citizens so that the country's social and economic development will become more meaningful.

Prevalence rates for many chronic health conditions were the highest for old adults. This study showed that those adults above forty years of age had almost all kinds of diseases up to the age of 61 and above. The highest prevalence rate falls on the 40-45 age groups. This result supports the research done by Hayes et al. (2006) who pointed out that old people are more exposed to chronic diseases.

In terms of gender, it was found that the types of disease were related to gender. Overall, the occurrence of chronic diseases (heart, kidney, high blood pressure and diabetes) among men was higher. However, women had more cancer, followed by high blood pressure.

In terms of ethnicity, it was found that the types of diseases were related to ethnic group, namely more Malays contract diabetes followed by CHD, high blood pressure, cancer and kidney disease. This is in line with Geok (1994) findings that the types and prevalence of health risk factors vary somehow among the three main ethnic groups in peninsular Malaysia.

Our finding regarding smoking habit and diseases (CHD, kidney, high blood pressure, diabetes and cancer) was supported by Kirkland et al. (1999) who revealed that smoking is a major cause of disease.

This study also showed that those who have family diseases were more concerned about their health and the more frequent the illness comes, the more concerned the person was about their health. This result supports the study done by Kirkland et al. (1999).

Recommendations: Health programs need to be implemented in schools, public places (such as supermarkets, community halls) and workplace. Posters, banners and advertisements in mass media can be used to create health awareness. They are important to improve public health and the well being of the nation. Besides, the productivity of the country increases with healthier citizens as less people take sick-leaves. In addition, medical expenditures of companies and government healthcare subsidies would be reduced. Therefore, health programs could be seen as an investment for the nation.

However, some strategies should be adopted in health programs for them to be effective. It is recommended that the public health administrators in Malaysia should consider the findings of this research 
when developing public health programs. Firstly, public health programs for older people (especially those above 40 years' old) are in dire need as very high percentage $(85.8 \%)$ of them are having disease such as heart attack, kidney failure, diabetes. More focus should be given to those in 40-45 age groups as they face the most health problems. Secondly, men and women have different diseases; therefore, health programs should have different focus for different gender. Men should be given health information to prevent chronic disease such as heart attack, kidney failure, high blood pressure and diabetes. On the other hand, women should be given advice on how to prevent cancer and high blood pressure. Thirdly, different race have different diseases. For example, health programs should focus on CHD, high blood pressure, diabetes and cancer for Malays, particularly in the middle income group. Next, those with smoking habit could experience different types of disease. Public awareness should be created on the effect of smoking on the kidney. Lastly, public health administrators should focus on the key determinants of public health awareness, i.e., practice of healthy lifestyle, good diet and weight control. They may use them to plan programs focusing on these three factors, e.g., books, publications, videos, website on healthy lifestyle, good diet and weight management to provide information to the public.

This research is also useful for researchers. They could investigate the reasons for such high occurrence (85.8\%) of disease for those above 40 years old and the possible reasons of highest prevalence of health problems in the 40-45 age group. If they could identify the key factors causing these phenomenon (e.g., lifestyle, diet, workstres), they may be able to improve the health of the nation. In addition, the research can be replicated in other countries using the same method. The findings would be useful for health administrators and researchers in the country of study.

\section{CONCLUSION}

This study highlights the public health awareness among the elderly in an industrially developing country. Based on the research conducted, all the four null hypotheses $\left(\mathrm{HO}_{1}, \mathrm{HO}_{2} \mathrm{HO}_{3}, \mathrm{HO}_{4}\right)$ were rejected. Therefore, it can be concluded that there is a significant relationship between type of disease and gender, race and smoking habit.

\section{REFERENCES}

Awomeso, J.A., A.M. Taiwo, A.M. Gbadebo and A.O. Arimoro, 2010. Waste disposal and pollution management in urban areas: A workable remedy for the environment in developing countries. Am. J. Environ. Sci., 6: 26-32. DOI: 10.3844/ajessp.2010.26.32
Calle, E.E., C. Rodriquez, K. Walker-Thurmond and M.J. Thun, 2003. Overweight, obesity and mortality from cancer in a prospectively studied cohort of U.S. adults. N. Engl. J. Med., 348: 1625-1638. PMID: 12711737

Chee, H.L., M. Kandiah, M. Khalid, K. shamsuddin and J. Jamaluddin et al., 2004. Body mass index and factors related to overweight among women workers in electronic factories in Peninsular Malaysia. Asia Pacific J. Clin. Nut., 13: 248-254. PMID: 15331336

Geiss, L.S., D.B. Rolka and M.M. Engelgau, 2002. Elevated blood pressure among U.S. adults with diabetes, 1988-1994. Am. J. Preventive Med., 22: 42-48. PMID: 11777678

Geok, L.K., 1994. Ethnic characteristics of coronary heart disease risk factors and mortality in Peninsular Malaysia. Asia. Pacific. J. Clin. Nutr., 3: 93-98.

Hayes, D.K., C.H. Denny, N.L. Keenan, JB. Croft and A.A. Sundaram et al., 2006. Racial/ethnic and socioeconomic differences in multiple risk factors for heart disease and stroke in women: Behavioral risk factor surveillance system, 2003. J. Women's Health, 15: 1000-1008. PMID: 17125418

Issa, G.F., S.M. Hussain and H. Al-Bahadili, 2009. Economic efficiency analysis for information technology in developing countries. J. Comput. Sci., 5: 751-759. DOI: 10.3844/jcssp.2009.751.759

Kirkland, S.A., D.R. MacLean, D.B. Langille, M.R. Joffres and K.M. MacPherson et al., 1999. Knowledge and awareness of risk factors for cardiovascular disease among Canadians 55 to 74 years of age: Results from the Canadian heart health surveys, 1986-1992. Canadian Med. Associat. J., 161: 10-16.

Lip, G.Y., C. Luscomber, M. McCarry, I. Malik and G. Beevers, 1996. Ethnic differences in public health awareness, health perceptions and physical exercise: implications for heart disease prevention. Ethn. Health, 1: 47-53. PMID: 9395547

Naidu, B.R., Y.F. Ngeow and T. Pang, 2003. Ethnic distribution of Chlamydophila pneumoniae antibodies in a Malaysian population and possible correlation with coronary heart disease. Eur. J. Epidemiol., 18: 135-137. PMID: 12733835

Sumalatha, K. and D. Ramakrishnaiah, 2004. Sex bias in secondary school social studies textbooks: A case study in India. Am. J. Applied Sci., 1: 62-63. DOI: $10.3844 /$ ajassp.2004.62.63 